\title{
Viewpoint \\ Live or let die: oestrogen regulation of survival signalling in endocrine response
}

\author{
Alison J Butt ${ }^{1,2}$, Robert L Sutherland ${ }^{1,2}$ and Elizabeth A Musgrove ${ }^{1,2}$ \\ ${ }^{1}$ Cancer Research Program, Garvan Institute of Medical Research, St. Vincent's Hospital, Darlinghurst, New South Wales, Australia \\ ${ }^{2}$ St. Vincent's Clinical School, Faculty of Medicine, University of New South Wales, Australia
}

Corresponding author: Alison J Butt, abutt@garvan.org.au

Published: 26 October 2007

This article is online at http://breast-cancer-research.com/content/9/5/306

(c) 2007 BioMed Central Ltd

Breast Cancer Research 2007, 9:306 (doi:10.1186/bcr1779)

\begin{abstract}
The growth of both normal and neoplastic tissues is determined by a balance between cell proliferation and cell death. Thus, understanding how these processes not only drive tumour growth dynamics but also influence therapeutic responsiveness may aid in the development of more effective cancer treatments. Oestrogen is a major aetiological factor in the development and progression of breast cancer, and its effects in driving breast cancer cell proliferation have been extensively studied. What is less well understood is how oestrogen's role as a survival factor influences breast tumour growth and response to therapy. Recent gene expression profiling studies in breast cancer cohorts have suggested that aberrant apoptotic signalling may play a role in responsiveness to endocrine therapies. Thus, further elucidation of this process may lead to identification of clinically relevant end-points to determine and delineate therapeutic response in breast cancer patients.
\end{abstract}

\section{Introduction}

Several recent studies have emphasized the potential of gene expression profiling to predict both outcome and therapeutic responsiveness in breast cancer patients $[1,2]$. Analyses of the potential function of genes within these predictive gene signatures have highlighted some of the fundamental processes that not only are involved in determining the biological behaviour of breast cancer but also (and perhaps more importantly from a clinical perspective) influence the response to therapy. As one may predict, these signatures are predominated by classes of genes that are involved in cell cycle regulation and mitogenic signalling. However, there is emerging evidence that aberrant apoptotic signalling may also have a role to play, reopening the debate on the importance of this process in determining endocrine responsiveness in breast cancer.

\section{Oestrogen, anti-oestrogens and apoptosis: the evidence}

Unlike its well characterized mitogenic effects, the influence of oestrogen-mediated survival signalling on the malignant process in the breast has been relatively understudied.
Oestrogen has direct, inhibitory effects on the apoptotic machinery in breast cancer cells, including transcriptional repression of the pro-apoptotic molecules Bak, Bik and caspase- 9 [3] and increased expression of anti-apoptotic $\mathrm{Bcl}-2$ via oestrogen-response elements in the $B C L-2$ coding sequence [4]. There is also evidence of ligand-independent crosstalk between oestrogen and growth factor intracellular signalling cascades, particularly those mediated by the erbB family of receptor tyrosine kinases, which leads to activation of survival pathways via activation of phosphatidylinositol 3kinase [5]. Consequently, regression of breast cancer cell line (MCF-7 and ZR75-1) derived xenografts after oestrogen withdrawal or anti-oestrogen treatment is associated with induction of apoptosis [6,7], and several in vitro studies have identified components of pro-apoptotic pathways that are induced by anti-oestrogens in breast cancer cells [8]. These latter studies have focused predominantly on the intrinsic apoptotic pathway, and include modulation of expression of Bcl-2 family members and changes in mitochondrial membrane potential [8]. However, these effects generally are observed at ligand concentrations that are unlikely to be experienced by tumour cells in vivo, and thus the mechanisms of oestrogen receptor dependent, antioestrogen induced apoptosis and their clinical relevance remain to be fully defined.

\section{Do apoptotic pathways influence endocrine responsiveness?}

Clinical studies aimed at determining the role played by apoptosis in the response to endocrine therapies for breast cancer have often revealed conflicting data. For example, Reimer and coworkers [9] reported an association between the death receptor Fas, Fas ligand and resistance to tamoxifen. Also, others have reported a decrease in expression of survival genes in breast cancers after neoadjuvant treatment with aromatase inhibitors [10]. However, studies of larger cohorts of patients treated with either aromatase inhibitors or tamoxifen have identified either no significant 
change [11] or, in a separate study, decreased apoptosis rates following treatment with aromatase inhibitors [12].

These differing results may be due to a number of confounding issues. First, there is an inherent difficulty in accurately monitoring the dynamics of apoptosis in vivo, in which apoptotic cells are rapidly cleared by macrophages and neighbouring cells. Second, the interpretation of these data may also be affected by the assumption that only tumour regression is an indication of increased apoptosis, whereas stable disease is maintained predominantly by decreased proliferation. In fact, studies in animal models have demonstrated that changes in tumour growth dynamics similar to those observed in clinically stable disease are associated with both a reduction in proliferation and an increase in apoptosis [7,13]. This issue has been addressed to some extent by examining the apoptotic/mitotic ratio [14], and data, albeit limited, from clinical studies have demonstrated that tumour responses to tamoxifen are positively correlated with this index [15]. However, the relationship between proliferation and apoptosis can also depend on the growth conditions of the tumour. For example, rapidly proliferating tumours can exhibit elevated apoptosis levels because of an increasingly hypoxic microenvironment. Third, there has been a reliance on single markers of apoptosis, such as Bcl-2 expression, as determinants of response. Although the latter is a transcriptional target of oestrogen and its expression generally correlates inversely with the induction of apoptosis, because it is only one component of a complex apoptotic signalling cascade it may underestimate the extent of the apoptotic response. In addition, further functional characterization of many mediators of apoptotic signalling has revealed that they also play a role in other cellular processes such as cell cycle progression and DNA repair, making it difficult to determine whether it is their apoptotic function per se that is driving the tumour response. This may partly explain the somewhat counterintuitive reports of high Bcl-2 expression being associated with better clinical response to tamoxifen [16], because increased $\mathrm{Bcl}-2$ may merely reflect a more oestrogen-sensitive cancer.

The advent of gene expression profiling, together with the more recent introduction of functional classification of microarray datasets, has enabled researchers to gain greater insight into the underlying processes that drive neoplastic growth and influence therapeutic responsiveness and outcome. It also has the potential to provide an independent means of assessing the role played by apoptotic signalling in these events. Although predominated by gene sets involved in proliferation and mitogenic signalling, several recent studies in breast cancer cohorts have identified prognostic signatures that involve cell death and cell survival signalling $[17,18]$, and a limited number of studies have more specifically identified signatures that are predictive of endocrine responsiveness. Jansen and coworkers [19] identified a predictive gene signature for tamoxifen responsiveness in a cohort of breast cancer patients with oestrogen receptor positive recurrent disease. Functional annotation revealed that about $14 \%$ of these genes had a reported role in mediating cell death or cell survival. Overall, although both pro-apoptotic and anti-apoptotic changes in gene expression were observed, the authors concluded that tamoxifen resistance was associated with an inhibition of apoptosis. Genes involved in survival signalling, namely BCL2, BAG1 and Survivin, also formed part of a 16-gene classifier identified by Paik and colleagues [20] that predicted the risk for recurrence in patients receiving adjuvant tamoxifen. However, apoptosis was not identified as a separate functional cluster in this study, making it difficult to assess the importance of the apoptotic process in determining the clinical response.

Although it may be premature to interpret fully the significance of these studies, they do suggest that regulators of survival and apoptosis may have some impact on therapeutic responsiveness in breast cancer. However, utilizing these data to provide greater mechanistic insight into the processes that drive therapeutic responsiveness may require a hypothesis driven, 'bottom up' approach that starts with a functional end-point and works toward determining its clinical relevance [2]. Furthermore, given the significant influence of post-translational mechanisms in regulating apoptotic signalling cascades, changes at the level of gene expression are likely to have limited utility or, at best, underestimate the influence of apoptosis on the response to endocrine therapies. Clearly, further studies are warranted, adopting an integrated, multifaceted approach that takes into account the unique aspects of cell death regulation outlined above, in order to assess more accurately the impact that apoptosis has on endocrine responsiveness. Such studies not only will give further insight into the underlying biology of breast cancer, but they may also provide useful clinical markers of therapeutic response and enhance our understanding of the factors that influence endocrine resistance.

\section{Competing interests}

The authors declare that they have no competing interests.

\section{References}

1. Sims $A H$, Ong KR, Clarke RB, Howell A: High-throughput genomic technology in research and clinical management of breast cancer. Exploiting the potential of gene expression profiling: is it ready for the clinic? Breast Cancer Res 2006, 8: 214.

2. Loi S, Piccart M, Sotiriou C: The use of gene-expression profiling to better understand the clinical heterogeneity of estrogen receptor positive breast cancers and tamoxifen response. Crit Rev Oncol Hematol 2007, 61:187-194.

3. Frasor J, Danes JM, Komm B, Chang KCN, Lyttle CR, Katzenellenbogen BS: Profiling of estrogen up- and down-regulated gene expression in human breast cancer cells: insights into gene networks and pathways underlying estrogenic control of proliferation and cell phenotype. Endocrinology 2003, 144:4562-4574.

4. Perillo B, Sasso A, Abbondanza C, Palumbo G: 17 $\beta$-estradiol inhibits apoptosis in MCF-7 cells, inducing bcl-2 expression via two estrogen-responsive elements present in the coding sequence. Mol Cell Biol 2000, 20:2890-2901. 
5. Butt AJ, McNeil CM, Musgrove EA, Sutherland RL: Downstream targets of growth factor and oestrogen signalling and endocrine resistance: the potential roles of c-Myc, cyclin D1 and cyclin E. Endocr Relat Cancer 2005, Suppl 1:S47-S59.

6. Kyprianou N, English HF, Davidson NE, Isaacs JT: Programmed cell death during regression of the MCF-7 human breast cancer following estrogen ablation. Cancer Res 1991, 51:162166.

7. Cameron DA, Ritchie AA, Langdon S, Anderson TJ, Miller WR: Tamoxifen induced apoptosis in ZR-75 breast cancer xenografts antedates tumour regression. Breast Cancer Res Treat 1997, 45:99-107.

8. Mandlekar S, Kong A-NT: Mechanisms of tamoxifen-induced apoptosis. Apoptosis 2001, 6:469-477.

9. Reimer T, Koczan D, Muller H, Friese K, Thiesen H-J, Gerber B: Tumour Fas ligand:Fas ratio greater than 1 is an independent marker of relative resistance to tamoxifen therapy in hormone receptor positive breast cancer. Breast Cancer Res 2002, 4: R9.

10. Ellis MJ, Rosen E, Dressman H, Marks J: Neoadjuvant comparisons of aromatase inhibitors and tamoxifen: pretreatment determinants of response and on-treatment effect. J Steroid Biochem Mol Biol 2003, 86:301-307.

11. Dowsett M, Smith IE, Ebbs SR, Dixon JM, Skene A, Griffith C, Boeddinghaus I, Salter J, Detre S, Hills $M$, et al.: Short-term changes in Ki-67 during neoadjuvant treatment of primary breast cancer with anastrozole or tamoxifen alone or combined correlate with recurrence-free survival. Clin Cancer Res 2005, 11:951s-958s.

12. Dowsett M, Smith IE, Ebbs SR, Dixon JM, Skene A, Griffith $C$, Boeddinghaus I, Salter J, Detre S, Hills M, et al.: Proliferation and apoptosis as markers of benefit in neoadjuvant endocrine therapy of breast cancer. Clin Cancer Res 2006, 12:1024s1030s.

13. Johnston SR, Boeddinghaus IM, Riddler S, Haynes BP, Hardcastle IR, Rowlands M, Grimshaw R, Jarman M, Dowsett M: Idoxifene antagonizes estradiol-dependent MCF-7 breast cancer xenograft growth through sustained induction of apoptosis. Cancer Res 1999, 59:3646-3651.

14. Cameron DA, Ritchie AA, Miller WR: The relative importance of proliferation and cell death in breast cancer growth and response to tamoxifen. Eur J Cancer 2001, 37:1545-1553.

15. Cameron DA, Keen JC, Dixon JM, Bellamy C, Hanby A, Anderson TJ, Miller WR: Effective tamoxifen therapy of breast cancer involves both antiproliferative and pro-apoptotic changes. Eur J Cancer 2000, 36:845-851.

16. Elledge RM, Green S, Howes L, Clark GM, Berardo M, Allred DC Pugh R, Ciocca D, Ravdin P, O'Sullivan J, et al.: bcl-2, p53, and response to tamoxifen in estrogen receptor-positive metastatic breast cancer: a Southwest Oncology Group study. J Clin Oncol 1997, 15:1916-1922.

17. Wang Y, Klijn JG, Zhang Y, Sieuwerts AM, Look MP, Yang F, Talantov D, Timmermans M, Meijer-van Gelder ME, Yu J, et al.: Gene-expression profiles to predict distant metastasis of lymph-node-negative primary breast cancer. Lancet 2005, 365:671-679.

18. Glinsky GV, Berezovska O, Glinskii AB: Microarray analysis identifies a death-from-cancer signature predicting therapy failure in patients with multiple types of cancer. J Clin Invest 2005, 115:1503-1521.

19. Jansen MPH, Foekens JA, van Staveren IL, Dirkzwager-Kiel MM, Ritstier K, Look MP, Meijer-van Gelder ME, Sieuwerts AM, Portengen H, Dorssers LCJ, et al.: Molecular classification of tamoxifen-resistant breast carcinomas by gene expression profiling. $J$ Clin Oncol 2005, 23:732-740.

20. Paik S, Shak S, Tang G, Kim CH, Baker J, Cronin M, Baehner FL, Walker MG, Watson D, Park T, et al:: A multigene assay to predict recurrence of tamoxifen-treated, node-negative breast cancer. N Engl J Med 2004, 351:2817-2826. 